satisfactorily fed in the required mode by this method.

Radiotherapeutic Research Unit,

$$
\text { G. R. NEWBERY }
$$

Medical Research Council,

Hammersmith Hospital, London, W.12.

Research Laboratories,

General Electric Co., Ltd., Wembley.

Dec. 16.

1 Fry, et al., Nature, 160, 351 (1947).

' Allen and Symonds, Proc. Phys. Soc., 59, 622 (1947).

${ }^{3}$ Willshaw, et al., J. Inst. Elect. Eng., Pt. IIIA, 93, No. 5, 996 (1946).

\section{Fission Products of $\mathbf{U}^{233}$}

Experiments have been described ${ }^{1,2}$ which give data for the fission products of $U^{235}$ produced in thermal neutron irradiation of natural uranium. Recently, a new radioactive series, not present in Nature, has been reported ${ }^{3,4}$. Seaborg has shown that $\mathrm{U}^{233}$, a member of this series, is fissile with neutrons. The following is a summary of the results of a survey of the longer-lived fission products of $U^{233}$. The data were obtained in conjunction with those previously raported ${ }^{1}$, but could not be released for publication at that time.

The relative yields of the fission products are given directly by the equilibrium activities for an infinitely long bombardment at a constant rate. The yield of $\mathrm{Ba}^{140}$ from the fission of $\mathrm{U}^{235}$ in natural uranium is taken as a reference. Three samples were irradiated simultaneously, one $\mathrm{U}^{233}$ and two natural uranium samples. In order to facilitate direct comparison of the fission-product activities in the natural uranium and $U^{233}$ samples, the weights of the respective samples used were such that the number of fissions produced in each were equal.

After irradiation, a chemical separation of each element lying between arsenic and praseodymium was made. Thirty-one active isotopes were found and identified by their half-lives and their $\beta-, \gamma$-ray absorption characteristics. In all cases, identical activities were observed in the natural and $U^{233}$ samples.

The fission yields for $U^{233}$ are presented in the accompanying table together with those for $\mathrm{U}^{235}$. As with $U^{235}$, a plot of fission yield against mass number shows a double-humped curve indicating a light group and a heavy group.

FISSION YIELDS FOR U $U^{233}$ AND U ${ }^{285}$

\begin{tabular}{|c|c|c|c|}
\hline Mass number & $\mathrm{U}^{285}$ & $\mathrm{U}^{283}$ & $\begin{array}{c}\text { Active isotope } \\
\text { determined }\end{array}$ \\
\hline $\begin{array}{r}89 \\
90 \\
91 \\
95 \\
103 \\
106 \\
111 \\
(123) \\
(123) \\
127 \\
125 \\
129 \\
131 \\
132 \\
137 \\
(136) \\
140 \\
144 \\
147\end{array}$ & 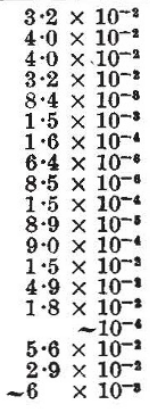 & $\begin{array}{r}4 \cdot 1 \times 10^{-2} \\
3 \cdot 7 \times 10^{-2} \\
4 \cdot 1 \times 10^{-2} \\
3 \cdot 9 \times 10^{-2} \\
2 \cdot 1 \times 10^{-8} \\
6 \cdot 4 \times 10^{-4} \\
1 \cdot 5 \times 10^{-4} \\
1 \cdot 9 \times 10^{-8} \\
2 \cdot 5 \times 10^{-8} \\
6 \cdot 7 \times 10^{-4} \\
6 \cdot 0 \times 10^{-4} \\
2 \cdot 2 \times 10^{-3} \\
2 \cdot 4 \times 10^{-2} \\
4 \cdot 9 \times 10^{-2} \\
1 \cdot 8 \times 10^{-2} \\
6 \cdot 7 \times 10^{-8} \\
6 \cdot 7 \times 10^{-2} \\
2 \cdot 2 \times 10^{-8} \\
26 \times 10^{-8}\end{array}$ & $\begin{array}{rll}55 \mathrm{~d} & \mathrm{Sr} \\
\sim 30 \mathrm{y} & \mathrm{Sr} \\
61 \mathrm{~d} & \mathrm{Y} \\
65 \mathrm{~d} & \mathrm{Zr} \\
37 \mathrm{~d} & \mathbf{R u} \\
290 \mathrm{~d} & \mathbf{R u} \\
7 \cdot 5 \mathrm{~d} & \mathrm{Ag} \\
\sim 18 \mathrm{~d} & \mathrm{Sn} \\
136 \mathrm{~d} & \mathrm{Sn} \\
90 \mathrm{~d} & \mathrm{Te} \\
\sim 10 \mathrm{y} & \mathrm{Sb} \\
32 \mathrm{~d} & \mathrm{Te} \\
8 \cdot 1 \mathrm{~d} & \mathrm{I} \\
2 \cdot 3 \mathrm{~h} & \mathrm{I} \\
33 \mathrm{y} & \mathrm{Cs} \\
\sim 20 \mathrm{~d} & \mathrm{Cs} \\
40 \mathrm{~h} & \mathrm{La} \\
290 \mathrm{~d} & \mathrm{Ce} \\
\sim 4 & \mathrm{y} & 61\end{array}$ \\
\hline
\end{tabular}

In $\mathrm{U}^{233}$ fission the groups have a similar shape to those for $U^{235}$ but are one unit lower on the mass scale. The maxima of the fission-yield curves are approximately the same in all cases, being approximately $6 \times 10^{-2}$.

A detailed account of the investigation is to be published.

Atomic Energy Project,

NTational Research Council, Chalk River, Ontario. Dec. 6.

${ }^{1}$ Grummitt, W. E., and Wilkinson, G., Nature, 158, 163 (1946).

2 Grummitt, W. E., Gueron, J., Wilkinson, G., and Yaffe, L., Can. J. Research, 25, B, 364 (1947).

${ }^{3}$ Hageman, F., Katzin, L. I., Studier, M. H., Ghiorso, A., and Seaborg, G. T., Phys. Rev., 72, 252 (1947).

- English, A. C., Cranshaw, T. E., Demers, P., Harvey, J. A., Hincks, E. P., Jelley, J. V., and May, A. N., Phys. Rev., '72, 253 (1947). ${ }^{5}$ Seaborg, G. T., Gosman, J. W., and Stoughton, R. W., Phys. Rev., 11, 378 (1947).

\section{Fluorescence of Highly Insulating Dielectrics Produced by $X$ - and $\gamma$-Radiations}

IN the course of experiments designed to study photographically the secondary electron emission from various light-atom materials when they are irradiated with high-voltage $\mathrm{X}$-rays, we have found that under certain radiation conditions some highly insulating dielectrics fluoresce when so irradiated, visible and possibly ultra-violet light being emitted. Polystyrene in the commercial form known as 'Distrene' shows the phenomenon quite markedly.

In our first experiments, using $\mathrm{X}$-rays generated at $200 \mathrm{kVp}$. (half-value layer, $2 \mathrm{~mm}$. copper), the photographic blackening due to secondary electronic emission ${ }^{1,2,3}$ was being examined for a range of lightatom materials which included amber, 'Perspex', paraffin wax, 'Alkathene' and 'Distrene', and for such elements as carbon, sulphur, aluminium, copper, silver, tin, gold and lead. The density of blackening obtained for the light-atom materials was much as one would theoretically expect with the exception of 'Distrene'; for this material the density was almost as great as that for copper. Various samples were used with always the same result. It was suggested by Dr. F. W. Spiers that the extra unexpected density might be due to fluorescent radiation, and this is so. A single layer of black paper was found to absorb the radiation and reduce the density of blackening to expected values; the transmission through various thicknesses of glass suggested that some of the radiation might be ultra-violet as well as visible.

The same light-atom materials were examined visually in the dark while they were irradiated with X-rays. No definite fluorescence could be seen from amber, only a faint suggestion was seen from paraffin wax, 'Perspex', and 'Alkathene'; but quite a strong diffuse whitish fluorescence was observed from 'Distrene'. Similar observations were made using $\mathrm{X}$-rays generated at $110 \mathrm{kVp}$. and $60 \mathrm{kVp}$. No apparent afterglow was seen; as the X-ray beam was switched off so the fluorescence disappeared.

Similar experiments were made in the dark using the gamma-ray beam from a 2-gm. radium mass unit. In this case a feeble fluorescence of a similar colour was seen from amber and 'Perspex' and quite a strong fluorescence from paraffin wax, 'Alkathene' and 'Distrene'. This fluorescence was also detectable 